\title{
Dairy producers' attitudes toward reproductive management and performance on Canadian dairy farms
}

\author{
J. Denis-Robichaud, ${ }^{*}$ R. L. A. Cerri, $†$ A. Jones-Bitton, ${ }^{*}$ and S. J. LeBlanc ${ }^{* 1}$ \\ *Department of Population Medicine, University of Guelph, Guelph, Ontario N1G 2W1, Canada \\ †Applied Animal Biology, Faculty of Land and Food Systems, University of British Columbia, Vancouver, BC V6T 1Z4, Canada
}

\begin{abstract}
The objectives of this study were to explore Canadian dairy producers' attitudes toward reproductive performance and challenges they perceive to be related to reproduction and reproductive management practices. A survey in both English and French was developed, validated, and administered to Canadian dairy farmers between March and May 2014 to collect general farm, reproduction management, and reproductive performance data, as well as opinions and perceptions about different facets of reproduction. Associations between management practices and the perceived importance of reproduction were tested using a logistic regression model. Thematic network analysis was used to identify themes from the open-ended survey questions about challenges concerning reproduction. Finally, questions that were answered on a Likert scale were graphically represented using diverging stacked bar charts. A total of 832 questionnaires were completed online and by mail, which represents approximately $7 \%$ of all dairy farms in Canada. Respondents that ranked reproduction in lactating dairy cows as 1 of the 3 most important challenges faced on their farm $(66 \%)$ were more likely to house their lactating cows in a tiestall and to have a lower herd annual 21-d pregnancy rate. Estrus detection and conception risk were 2 major themes raised and discussed by the respondents. Other concepts, including housing and milk production, were also perceived to affect estrus detection and conception risk. Whereas analysis of open-ended survey questions does not allow for quantification of the importance of different themes in the sample as a whole, it does show that respondents are aware of the multifactorial complexity of reproductive challenges on dairy farms. Improving performance was the main factor influencing decisions concerning reproduction for $80 \%$ of the respondents, and they adopted tools and technologies such as synchronization
\end{abstract}

Received December 7, 2016.

Accepted August 26, 2017.

${ }^{1}$ Corresponding author: sleblanc@uoguelph.ca programs and automated activity monitoring systems to improve herd reproductive performance. More research is required to describe how this performance is defined and perceived by the respondents, and how it relates to the actual variability of performance (i.e., pregnancy rate) among farms.

Key words: opinion, reproduction, survey, technology

\section{INTRODUCTION}

To be sustainable, dairy production must be economically profitable, result in a high-quality product, and take into account the animals, the environment and resources, and consumers (von Keyserlingk et al., 2013). Multiple tools and technologies have been developed over the past decades and adopted on dairy farms to manage reproduction and improve reproductive performance (Caraviello et al., 2006; Neves and LeBlanc, 2015; Denis-Robichaud et al., 2016). For example, automated activity monitoring (AAM) systems are used to detect estrus with adequate accuracy (Roelofs et al., 2005a; Løvendahl and Chagunda, 2010). The main reason for adopting AAM systems among surveyed Canadian dairy farmers in 2010 was dissatisfaction with reproductive performance (Neves and LeBlanc, 2015). The reasons for adopting timed AI programs have not been quantified, but reproductive hormones are widely used on dairy farms in North America to synchronize estrus or ovulation (Caraviello et al., 2006; Denis-Robichaud et al., 2016). Depending on the program and success of implementation relative to other reproduction management options, performance of timed AI is usually good to excellent (Nebel et al., 1994; Souza et al., 2008).

The economic impact of reproductive performance (Cabrera, 2014) makes the management of reproduction a key factor targeted by farmers and their advisors. Data that provide insights into producers' practices, perspectives, and priorities may be useful to farm advisors and may help to inform research questions in dairy science. Therefore, the objective of the current study was to describe dairy producers' attitudes toward reproductive performance and their perceptions 
of challenges related to reproduction and reproductive management practices.

\section{MATERIALS AND METHODS}

Information from a total of 832 Canadian dairy farms was collected in this cross-sectional study, using a bilingual (English and French) questionnaire reported previously [including supplemental data from Denis-Robichaud et al. (2016; http://dx.doi.org/10.3168/jds.2016 -11445); University of Guelph Research Ethics Board \#14JA048]. Briefly, the questionnaire was distributed across Canada from March to May 2014 by internet (FluidSurveys, Ottawa, Canada) and mail. A web link to the questionnaire was sent once to approximately 3,000 available email addresses of subscribers to the milk recording services in Canada by the DHIA organizations, without reminders or follow-up. Additionally, a printed advertisement card with the web address was sent to approximately 8,000 dairy farmers, included in The Milk Producer magazine, and included with the monthly milk recording service (DHIA) report, depending on the region. A paper copy of the questionnaire was also sent to 2,000 randomly selected milk recording subscribers with their monthly DHIA report. We did not receive any demographic data on the recipients of the email or mailed questionnaires. The estimated sampling frame reached with the 3 methods, including some overlap among the approaches, was approximately 9,000 dairy herds (11,962 dairy herds in Canada; Canadian Dairy Information Center, 2014).

In addition to the information about demographics, management practices, and reproductive performance reported previously (Denis-Robichaud et al., 2016), respondents were asked to give their opinions and perceptions of reproduction and reproductive management practices with open-ended and ranking questions, and ordinal 5-point (Likert) scale questions (e.g., for a given statement, respondents selected their degree of agreement: strongly disagree, disagree, no opinion, agree, or strongly agree). Respondents were asked to rank 9 different difficulties or challenges encountered on their farm according to its importance in their herd: lameness, calf health, mastitis, transition cow diseases, nutrition, heifer growth, reproduction of lactating dairy cows, culling rate, and reproduction of heifers.

Data entry for mail answers was done in Microsoft Access (Microsoft Corporation, Richmond, WA), and all data (mail and online) were collated into a Microsoft Excel (Microsoft Corporation) spreadsheet. Respondents were asked to give one-time access to their data from milk recording services. If they gave permission and a valid herd identification number, data on AI and pregnancy dates were entered into DairyComp
305 (VAS, Tulare, CA). Annual 21-d pregnancy rate (PR), 21-d insemination rate (IR), and conception risk (CR; probability of diagnosed pregnancy per AI) for the year 2013 were extracted from the software using a standardized voluntary waiting period of $50 \mathrm{~d}$ postpartum. This voluntary waiting period was chosen to have comparable $\mathrm{PR}$, insemination rate, and conception rate among herds. From the present data, the average reported voluntary waiting period in Canada was 57 DIM (Denis-Robichaud et al., 2016).

Statistical analyses were conducted using SAS 9.3 (SAS Institute, Cary, NC). Means, medians, and interquartile ranges (IQR; 1 st to 3 rd quartile) were calculated for continuous variables, and frequencies were calculated for binary and categorical variables. Univariable logistic regression models (PROC LOGISTIC in SAS) were built to identify factors associated with classifying reproduction of lactating dairy cows in the first 3 positions of the ranking, and a multivariable model was fitted using a backward elimination approach.

A thematic networks analysis (TNA) approach (Attride-Stirling, 2001; O'Cathain and Thomas, 2004) was used for the open-ended question, "Concerning reproduction in general, what do you think are the main difficulties or challenges?" This approach allowed for exploration of the issues and reproductive challenges on dairy farms and visual structuring of the textual data (Attride-Stirling, 2001). The answers provided by respondents were read, and basic themes describing the thematic content were formulated. Basic themes were then grouped within common organizing themes, which were in turn grouped within global themes according to current knowledge or explicit mention by the respondents. For example, basic themes for ovarian cyst, retained placenta, purulent vaginal discharge, metritis, pregnancy loss, and abortion were grouped under the organizing theme reproductive diseases, which connected with the global theme animals. These links between basic themes, organizing themes, and global themes represent the thematic network of ideas reported by the respondents.

Answers to Likert scale questions were used as outcomes in linear regression models (PROC GLM in SAS) to identify associations between the respondent's agreement with statements concerning reproduction and their management practices and farm characteristics (Norman, 2010). Location of the herd, barn type, reproductive management practice used for $>50 \%$ of AI in lactating cows, ranking of reproduction among self-assessed herd challenges, and annual herd PR were the variables offered to the regression models. These variables were chosen based on their plausible association with the models' outcome. Answers were represented graphically using diverging stacked bar charts 
(Robbins and Heiberger, 2011) for all respondents and by management practices or farm characteristics that remained in the models.

\section{RESULTS AND DISCUSSION}

\section{Respondents, Farm Characteristics, and Reproductive Management Practices}

A total of 832 Canadian dairy farmers completed the questionnaire (490 online, and 342 by mail), and 548 gave access to their milk recording services files. The response rate was estimated to be approximately $9 \%$, which represents $7 \%$ of all dairy farms in Canada. The percentage of unanswered questions concerning attitudes and opinions toward reproduction ranged from $2 \%$ for Likert scale questions to $21 \%$ for the open-ended question discussed in the current paper. As not all respondents answered all questions, the denominators for different variables varies, as noted.

Although the response rate appears to be low (Dillman et al., 2008), as presented previously (DenisRobichaud et al., 2016), respondents were representative of the Canadian dairy industry. Moreover, our reported sampling frame was the maximum possible number of contacts for our methods, and represented approximately $75 \%$ of the target population. The total number of respondents allowed for precise estimates of the proportions of responses. Briefly, respondents were from western provinces $(15 \%, \mathrm{n}=123)$, Ontario $(41 \%$, $\mathrm{n}=337)$, Québec $(42 \%, \mathrm{n}=347)$, and the Maritimes $(2 \%, \mathrm{n}=19)$. Farms had, on average, 77 lactating cows (median $=55, \mathrm{IQR}=40$ to 88$)$, and housed them in tiestall $(61 \%, \mathrm{n}=502)$, freestall $(37 \%, \mathrm{n}=302)$, or bedded pack $(2 \%, \mathrm{n}=22)$ barns. Visual estrus detection $(48 \%, \mathrm{n}=396)$, timed AI $(28 \%, \mathrm{n}=236)$, and AAM $(11 \%, \mathrm{n}=94)$, were used for $>50 \%$ of first or subsequent inseminations of lactating cows. The remaining farms $(13 \%, \mathrm{n}=106)$ did not use 1 practice for $>50 \%$ of inseminations. The average PR was $18 \%$ $(\mathrm{SD}=5$, median $=17, \mathrm{IQR}=14$ to 21$)$, insemination rate was $44 \%(\mathrm{SD}=12$, median $=45, \mathrm{IQR}=37$ to 52$)$, and conception rate was $41 \%(\mathrm{SD}=9$, median $=40$, $\mathrm{IQR}=35$ to 46$)$.

\section{Opinions and Attitudes Toward Reproduction}

Reproduction of lactating cows was ranked in the top 3 difficulties or challenges encountered by $66 \%$ $(496 / 753)$ of the respondents (Figure 1). The questionnaire was related specifically to reproduction, which could have biased the answer to this question by increasing the proportion of respondents ranking reproduction in the top difficulties or challenges. However, in a national survey on dairy cattle health (Bauman et al., 2016), Canadian dairy farmers ranked reproduction as the most important priority for research, which corroborates our findings.

In the multivariable logistic regression model, type of housing and PR were associated with classifying

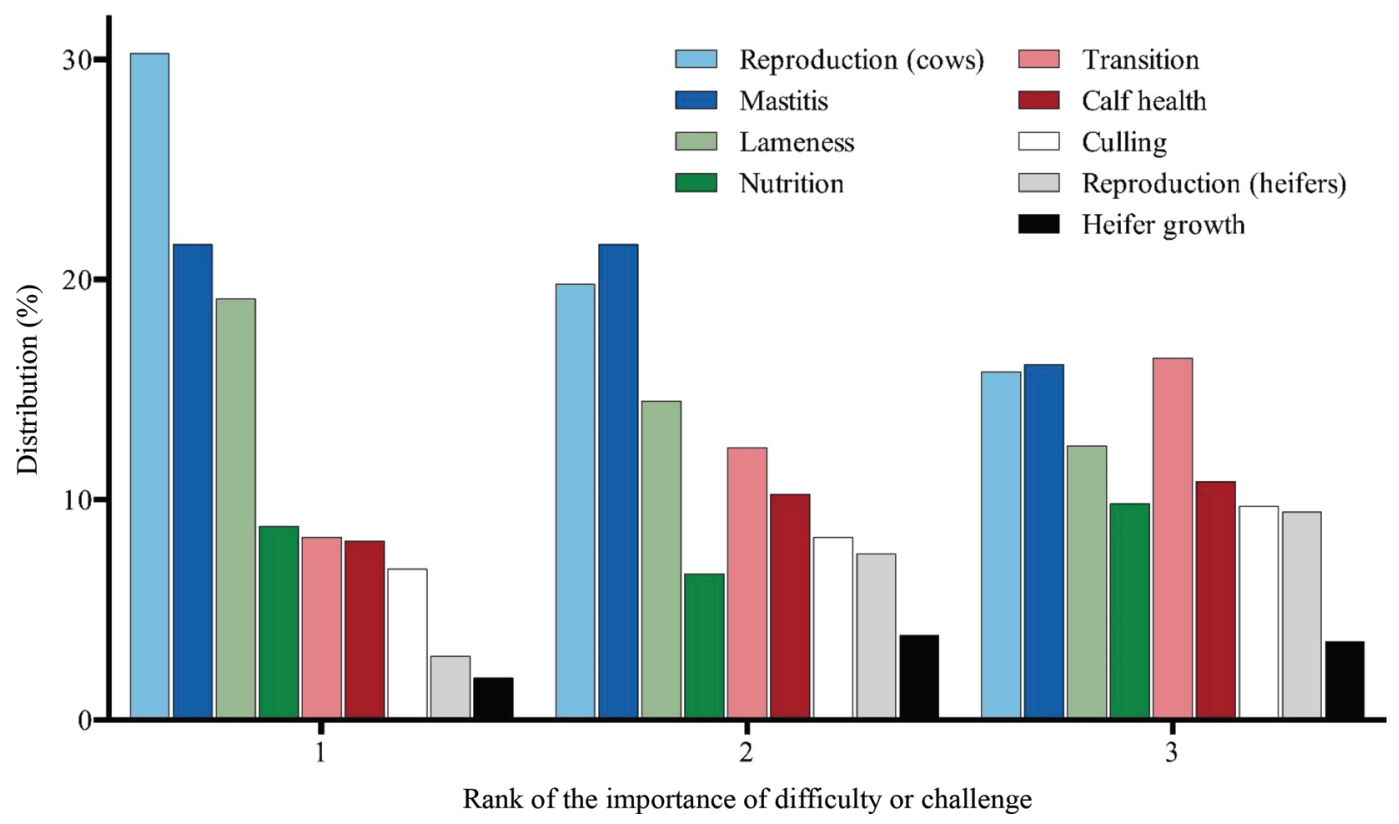

Figure 1. Distribution of the top 3 (of 9) management areas offered to Canadian dairy farmer respondents that were identified as challenges for their farm $(\mathrm{n}=792)$. Color version available online. 
reproduction of lactating dairy cows as one of the top 3 challenges (Table 1). Respondents housing their lactating cows in tiestall barns were more likely to rank reproduction as one of their top challenges than respondents housing their lactating cows in freestall barns. Estrous behaviors, such as mounting and standing to be mounted, cannot be expressed in tiestall housing unless the cows are allowed out of their stalls. Pasture access was provided by $30 \%$ of respondents in tiestall barns (Denis-Robichaud et al., 2016), which may explain, at least partly, why reproduction was a greater challenge in tiestall barns. Unsurprisingly, higher PR was associated with lower odds of ranking reproduction as a top challenge. Other variables were associated with classifying reproduction of lactating dairy cows as a main challenge in the univariable models (Table 1). These variables did not remain in the multivariable model $(P$ $>0.05)$, probably due to their association with either the type of housing or PR (Denis-Robichaud et al., 2016). Removing these variables from the multivariable model did not change the estimates of housing or PR by more than $10 \%$, suggesting that their confounding effect was minimal (Maldonado and Greenland, 1993).

Forty-six percent of the respondents (371/799) reported they were not meeting their targets for herd reproductive performance, which supports the notion that reproduction is a challenge for many dairy farmers. As expected, that proportion was higher on farms
Reproductive performance in my herd meets my target

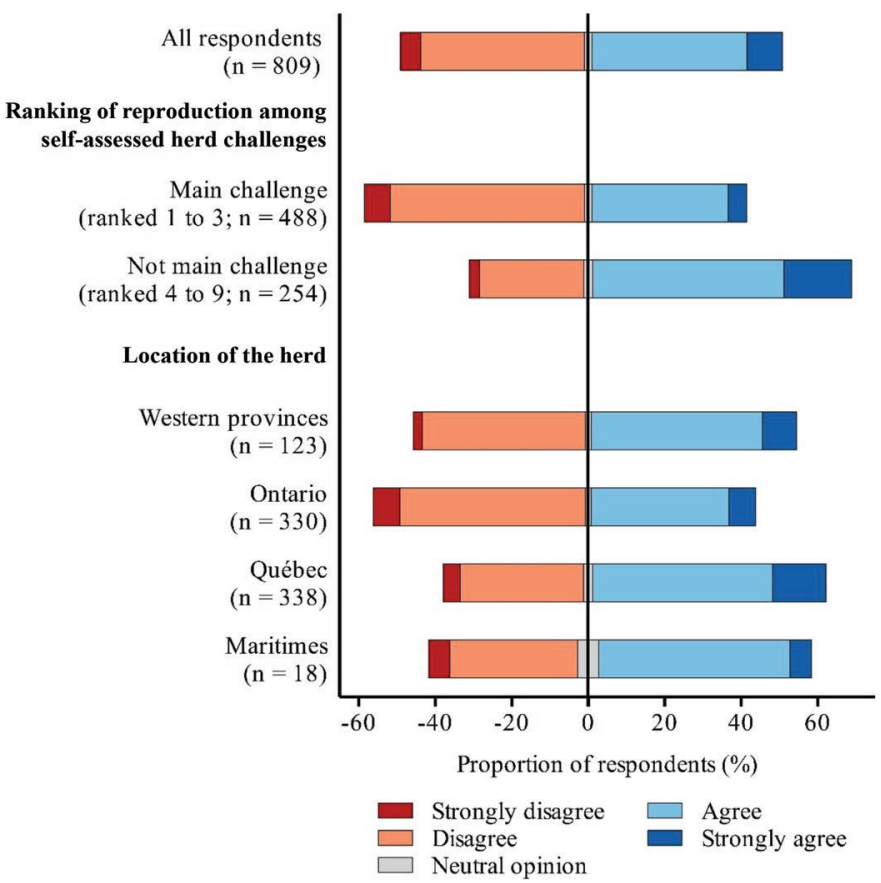

Figure 2. Distribution of satisfaction with herd reproduction performance among 809 dairy producers in Canada, by the rank of reproduction in the top 3 of the main challenges on their farm $(\mathrm{n}=742)$ and by geographical region $(\mathrm{n}=809)$. Color version available online.

Table 1. Univariable and multivariable logistic regression models of factors associated with ranking reproduction in lactating dairy cows as 1 of the top 3 difficulties or challenges in respondents' herds $(\mathrm{n}=504$ Canadian dairy producers $)$

\begin{tabular}{|c|c|c|c|c|c|c|}
\hline \multirow[b]{2}{*}{ Item } & \multicolumn{3}{|c|}{ Univariable models } & \multicolumn{3}{|c|}{ Multivariable model } \\
\hline & Odds ratio & $95 \% \mathrm{CI}$ & $P$-value & Odds ratio & $95 \% \mathrm{CI}$ & $P$-value \\
\hline \multicolumn{7}{|l|}{ Type of housing } \\
\hline Freestall & Referent & & & Referent & & \\
\hline Tiestall & 3.2 & $2.3-4.3$ & $<0.01$ & 3.7 & $2.5-5.5$ & $<0.01$ \\
\hline \multicolumn{7}{|c|}{ Main reproduction management practice } \\
\hline Visual estrus detection & Referent & & 0.01 & & & \\
\hline \multicolumn{7}{|l|}{ Geographic region } \\
\hline Western provinces & Referent & & & & & \\
\hline Ontario & 1.4 & $0.9-2.2$ & & & & \\
\hline Québec & 2.1 & $1.4-3.3$ & $<0.01$ & & & \\
\hline Maritimes & 3.9 & $1.1-14.3$ & & & & \\
\hline \multicolumn{7}{|l|}{ Age group of respondents } \\
\hline Under $30 \mathrm{yr}$ old & Referent & & & & & \\
\hline Increase of 20 milking cows & $0.9^{3}$ & $0.9-1.0$ & $<0.01$ & & & \\
\hline
\end{tabular}

${ }^{1} \mathrm{AAM}=$ automated activity monitor.

${ }^{2}$ The odds of ranking reproduction as 1 of the top 3 challenges decreased 0.8 times for each 5 -point increase in pregnancy rate.

${ }^{3}$ The odds of ranking reproduction as 1 of the top 3 challenges decreased 0.9 times for each 20 milking cow increase. 


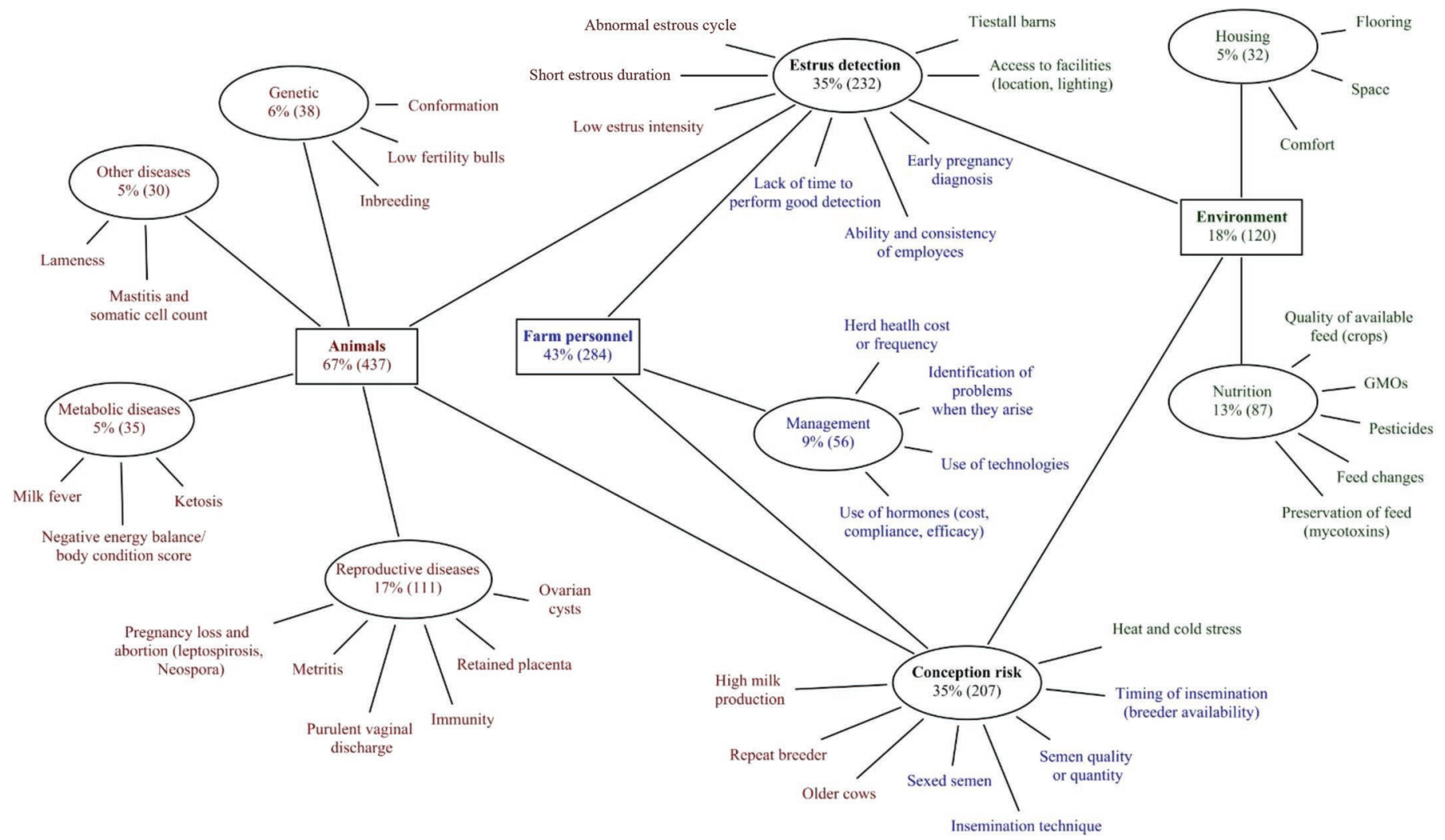

Figure 3. Nonhierarchical illustration of the thematic network for challenges and difficulties concerning reproduction reported by Canadian dairy farmers $(\mathrm{n}=657)$. The proportions (no.) of respondents with responses corresponding to global (squares) and organizing (circles) themes are presented, and each organizing theme is further described by basic themes obtained using thematic networks analysis for the question: "Concerning reproduction in general, what do you think are the main difficulties or challenges?" Two organizing themes, estrus detection and conception risk, were described by respondents to be shared between 3 of the global themes (animals, farm personnel, and environment). A description and exemplar quotes of the basic and organizing themes are available in the Supplemental Data (https://doi.org/10.3168/jds.201612416). Color version available online.

that ranked reproduction in the top 3 challenges that they encountered (58\%; Figure 2).

The open-ended question concerning the main difficulties and challenges for reproduction provided a detailed and nuanced understanding of what respondents $(\mathrm{n}=657)$ found challenging with reproduction. The TNA with basic (concepts), organizing, and global themes is presented in Figure 3. Most respondents mentioned 1 concept $(53 \%, \mathrm{n}=346)$, but $2(32 \%, \mathrm{n}=$ $213), 3(11 \%, \mathrm{n}=75), 4(3 \%, \mathrm{n}=19)$, or $5(1 \%, \mathrm{n}=4)$ different concepts were mentioned by some respondents in the response to the open-ended question. A description and exemplar quotes of the basic and organizing themes are available (Supplemental File S1; https:// doi.org/10.3168/jds.2016-12416). Basic themes were grouped under organizing themes such as estrus detection, conception risk, diseases, genetics, management, nutrition, and housing. In turn, these organizing themes related to the global themes of animals, farm personnel, or environment. Estrus detection and conception risk were mentioned on their own (e.g., "not seeing heat" or "getting cows pregnant"), but were also linked to the 3 global themes: the animals [e.g., "high-producers showing heat" and "getting cows pregnant (especially older hard-working cows)"], the farm personnel (e.g., "if the heat-detection person is away, no one else seems to be able to fill the gap" and "services per conception, AI tech is new and still learning"), and the environment (e.g., "expression of heats in tiestall barn"; Figure 3).

In explaining why estrus detection was a challenge, respondents mentioned short duration or subtle signs (low intensity of expression) of estrus, and abnormal estrus cycles or anovulation. Moreover, farmers reported having insufficient time to look for signs of estrus, and having difficulty finding employees with good ability to detect estrus in cows. Cows kept in tiestall barns, poorly lit barns, and heifer barns in remote locations were reported to pose a challenge to detection of estrus. These challenges reported by respondents are well aligned with previous research. For example, estrus 
duration is relatively limited (reported to be between 6.2 and $10.7 \mathrm{~h}$, with cows standing to be mounted 3.6 to 5.9 times per estrus; Lopez et al., 2004; Roelofs et al., 2005b; Løvendahl and Chagunda, 2010). Anovulation has been reported to have a negative effect on reproductive performance, with herd prevalence varying between 5 and 45\% (Walsh et al., 2007; Santos et al., 2009; Dubuc et al., 2012). To further add to the difficulty of identifying cows in estrus, the time spent dedicated to estrus detection has been reported to be between 36 and 75 min per day (Caraviello et al., 2006; Denis-Robichaud et al., 2016), which combined with short duration of estrus lends itself to missed estrus events. Reproductive performance has also been shown to be lower in tiestall than in freestall barns (Simensen et al., 2010; Denis-Robichaud et al., 2016).

Many elements were mentioned by respondents to explain why they found conception risk to be a major challenge. Older cows, repeat breeders, and cows with high milk yield were perceived as part of the problem, as were insemination technique and timing, semen quality and quantity, and environmental factors affecting fertility, such as heat stress (Figure 3); each of these is supported in the literature. For example, parity, high milk yield, and diseases are indeed associated with reduced fertility (Gröhn and Rajala-Schultz, 2000; Löf et al., 2014; Wiltbank and Pursley, 2014). The timing of insemination relative to the detection of estrus signs is also challenging due to the uncertainty of the timing of ovulation relative to observed signs (Van Eerdenburg et al., 2002; Roelofs et al., 2005a,b). Finally, heat stress is also well known to have a considerable effect on conception risk (Chebel et al., 2004; Schüller and Heuwieser, 2016).

The illustration of the TNA represents the links expressed by the respondents themselves, but additional relationships between themes likely exist (not represented in Figure 3). For example, conception risk is associated with estrus expression (Madureira et al., 2015; Pereira et al., 2016), and reproductive diseases are associated with anovulation (and consequently poor estrus detection) and also with lower conception risk (Walsh et al., 2007; Dubuc et al., 2012; Denis-Robichaud and Dubuc, 2015). Similar associations can be made with metabolic diseases (Walsh et al., 2007; Chapinal et al., 2012; Rutherford et al., 2016), nonmetabolic diseases (Walker et al., 2008; Morris et al., 2011), and, to a certain extent, genetic parameters (Bamber et al., 2009; Jeong et al., 2016). The TNA showed that producers recognized the complexity of the factors influencing reproductive performance on Canadian dairy farms; however, it is unclear to what degree respondents recognize the complexity of reproductive challenges and how they affect their management decisions on farm. A more thorough understanding of their perceptions could be achieved using focus groups, and this would serve to support research that is oriented toward farmers' needs and to direct knowledge translation and transfer projects. The results of an open-ended question cannot be interpreted as quantitatively representative of the population due to nonresponse bias, but they can give a good idea of the preoccupations of the respondents (Garcia et al., 2004).

Considering that estrus detection was an important challenge on participating farms, the use of tools to overcome this difficulty seems logical. Figure 4 shows that more respondents using timed AI as their main management practice thought it was harder to identify cows in estrus than respondents using other practices $(P<0.01)$. Interestingly, fewer respondents using AAM thought so, perhaps because they can use the system to enhance estrus detection. However, it is possible that the association between the main management practice and the reported ease of identifying cows in estrus may have been entangled with factors such as the type of housing. Briefly, respondents with tiestall housing found it harder to identify cows in estrus than respondents with freestalls $(P<0.01$; Figure 4$)$, and more timed AI was used in tiestall barns (36 and $17 \%$ of tiestall and freestall barns, respectively, used timed AI as their main management practice) and more AAM in freestall barns ( 1 and $27 \%$ of tiestall and freestall barns, respectively, used AAM as their main management practice). Whereas the use of AAM in freestall barns is easily explainable by the barn design, the greater prevalence of timed AI in tiestall barns was perhaps due to the challenges of detecting cows in estrus and the ease of use of timed AI protocols in tiestall barns. This cannot be ascertained given the cross-sectional design used here.

Not surprisingly, respondents using timed AI or AAM thought the tool they used produced a better pregnancy rate than visual estrus detection (Figure 5). A striking proportion of respondents not using AAM had a neutral opinion regarding the capacity of the system to produce higher PR than visual estrus detection, which likely reflects a lack of knowledge about this relatively new technology. In a previous survey, not being familiar with the systems available was a reason not to adopt AAM system, but was fifth in frequency after satisfied with herd reproductive performance, lack of perceived economic value, and did not think herd reproductive performance would improve (Neves and LeBlanc, 2015).

We did not collect detailed information on how respondents employed combinations of reproductive management tools or their rationale for their specific choices, but the great majority used at least some 


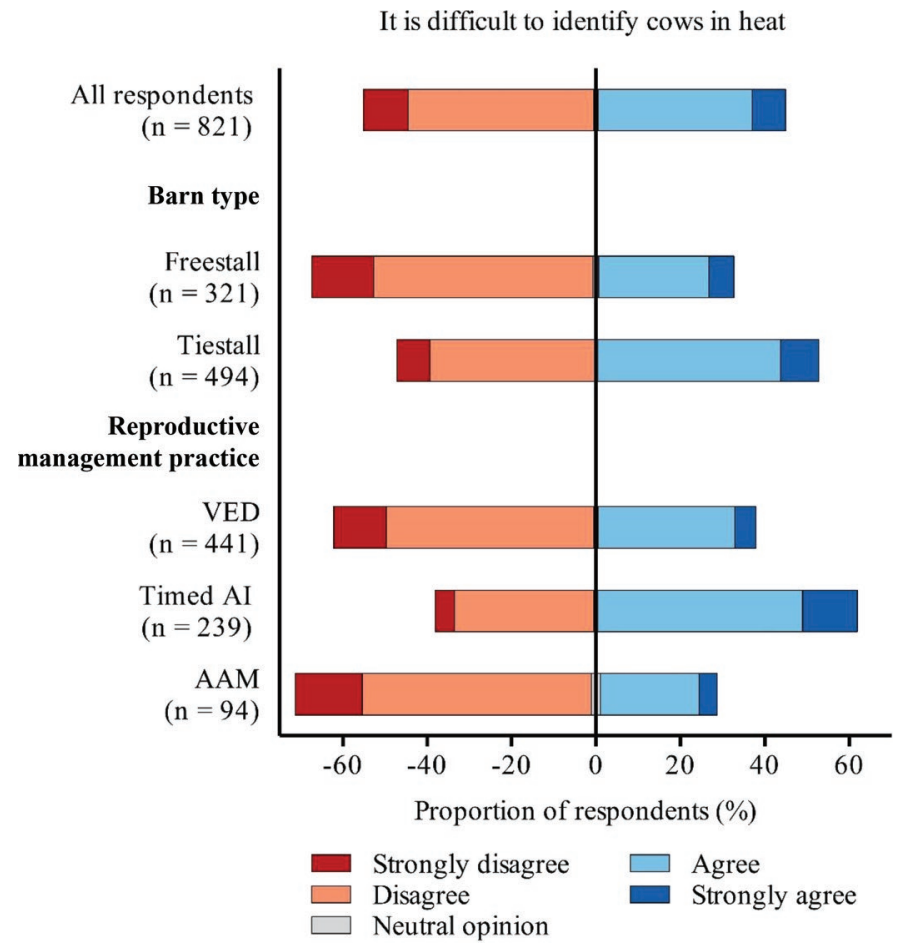

Figure 4. Opinions of 821 dairy producers in Canada on the difficulty of identifying cows in estrus by housing $(\mathrm{n}=815)$, and reproductive management practices used for $>50 \%$ of AI in lactating cows $[n=$ 774; visual estrus detection (VED), timed AI, or automated activity monitoring (AAM)]. Color version available online.

timed AI (Denis-Robichaud et al., 2016). Therefore, their responses to the questions in Figure 5 are likely colored by their chosen practices and experiences. For example, the perception of timed AI would likely be different in herds using it after estrus was not detected after a certain time (i.e., disproportionately in anovular cows) and herds in which it was the first-line tool for all cows; further differences may be expected depending, in the former example, on whether progesterone supplementation were part of the protocol.

Figure 6 represents various opinions on the use of reproductive hormones, which helps describe why respondents used different reproductive-management practices. For example, most respondents using timed AI not only thought synchronization programs were acceptable for them and consumers, but also that they were profitable and would not decrease cow fertility in the long term. On the contrary, respondents using AAM did not find synchronization programs as acceptable or profitable; respondents using visual estrus detection were more divided. It is not clear how respondents interpreted the questions regarding the routine use of synchronization programs, as programs could be routinely and systematically used for first or all inseminations (which was the intended meaning), or routinely
On average, timed AI produces higher pregnancy rates than visual observation of heat

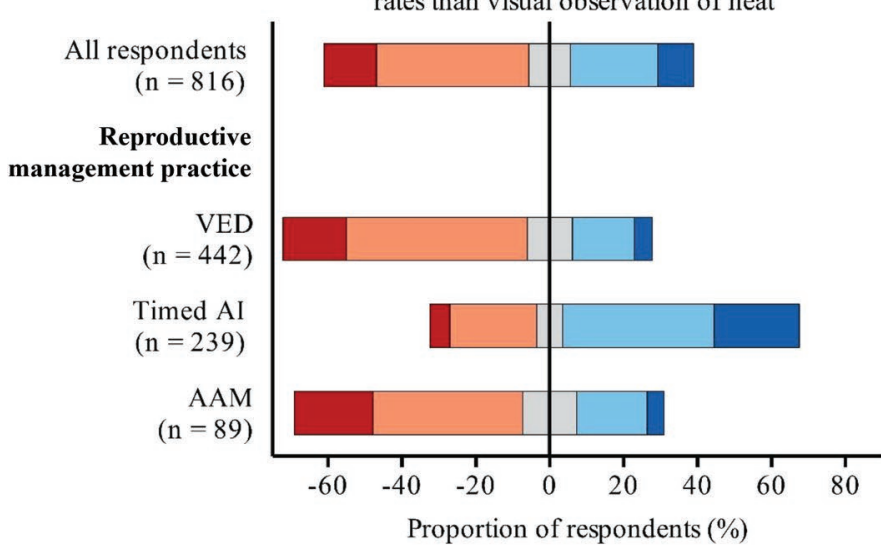

On average, AAM produces higher pregnancy rates than visual observation of heat

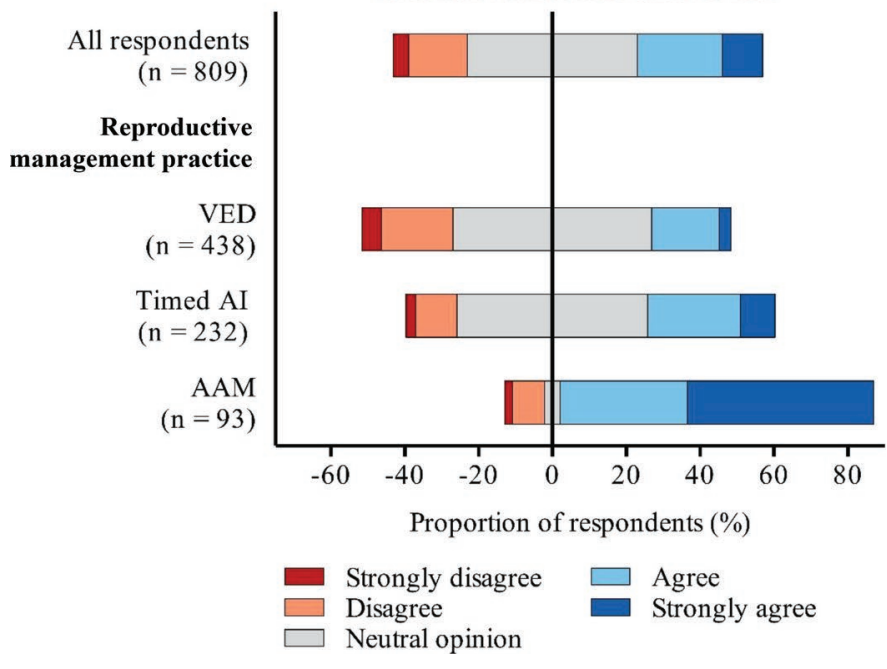

Figure 5. Opinions of Canadian dairy producers on the capacity of timed $\mathrm{AI}$ and automated activity monitoring (AAM), respectively, to produce better pregnancy rates than visual estrus detection (VED), presented by reproductive management practices used for $>50 \%$ of AI in lactating cows (VED, timed AI, or AAM). Color version available online.

but selectively for specific cows or conditions (e.g., cows with cystic ovarian condition). We acknowledge that the manner in which respondents used synchronization programs and their understanding of the question affected interpretation of these responses.

Public perception did not have a high influence on respondents' decisions about management of reproduction (Figure 7). Performance was valued over economics and labor by $80 \%$ of the respondents. The question did not probe what performance specifically meant for the respondents. Different measures are used by dairy farmers to evaluate reproductive performance. Pregnancy rate is the measure that gives the least-biased estimates of reproductive performance, as it accounts 
Routine use of synchronization programs is acceptable to consumers

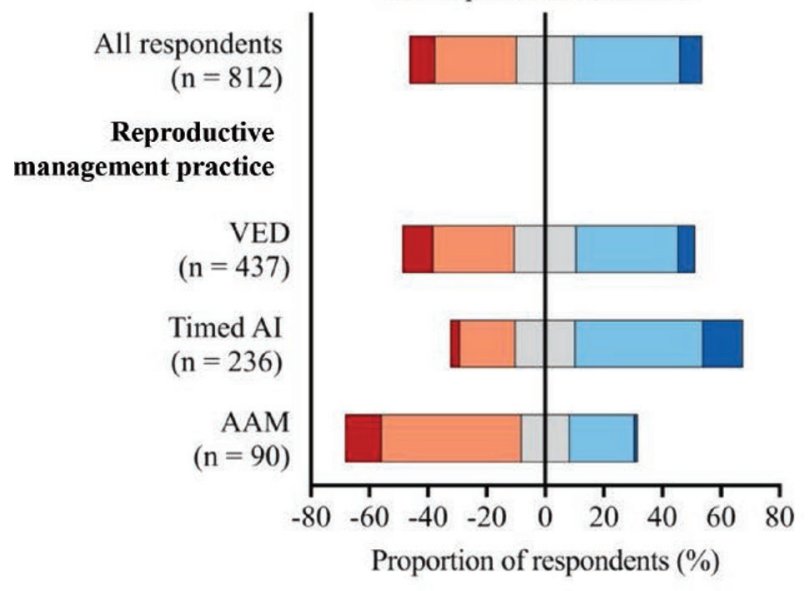

Routine use of synchronization programs is acceptable to me

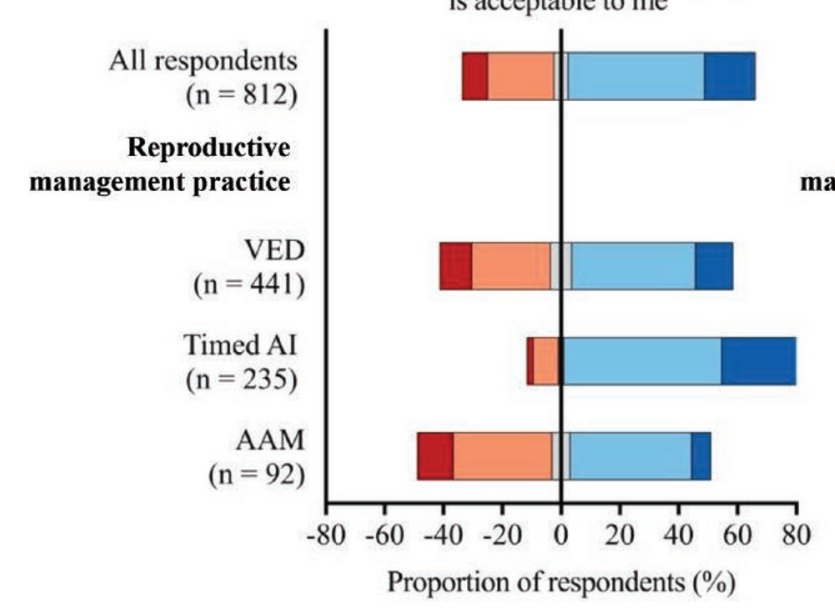

Routine use of synchronization programs is profitable for my herd

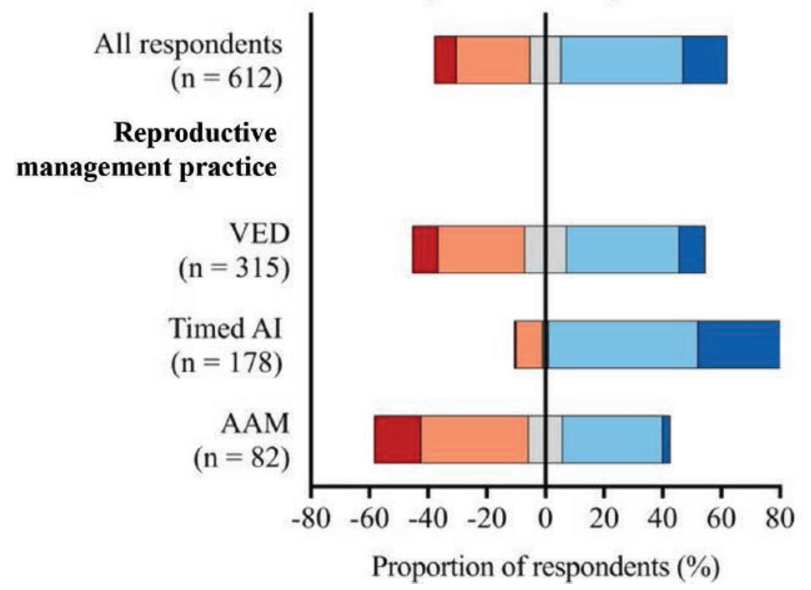

Use of synchronization programs will decrease cow fertility in the long term

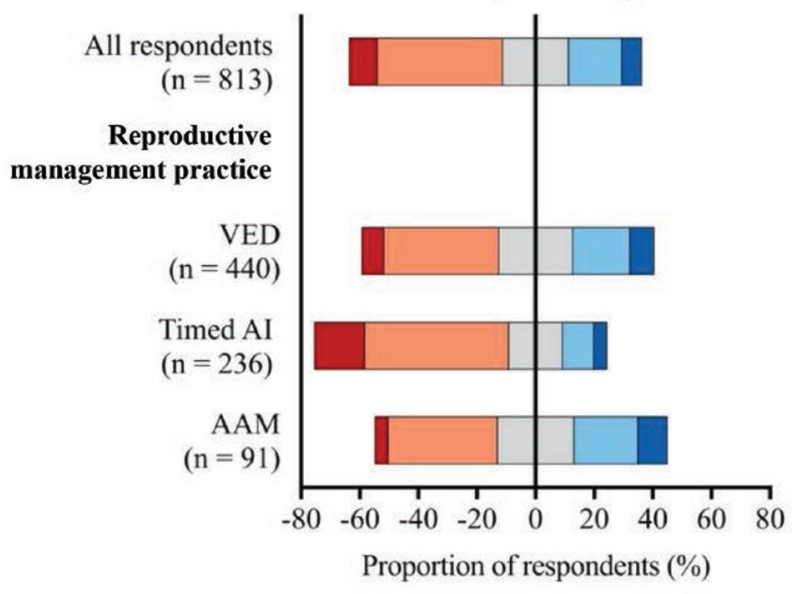

In 5 years, I will be using less synchronization in my herd

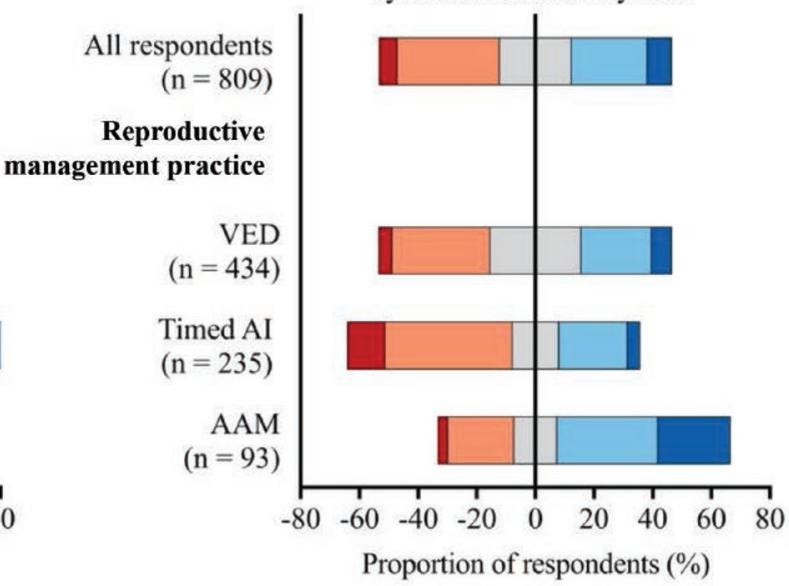

Figure 6. Opinions of Canadian dairy producers on the use, perception, and effect of synchronization programs presented by use of hormones, and by reproductive management practices used for $>50 \%$ of AI in lactating cows [visual estrus detection (VED), timed AI, or automated activity monitoring (AAM)], and use of hormones. Color version available online. 
for all cows at risk with minimal lag, as it is constantly updated with the latest available data, but is not necessarily used by producers. Sixty-one percent of the respondents $(\mathrm{n}=489)$ reported looking at their herd annual PR weekly or monthly, $15 \%$ did so every 2 to 6 mo, and $24 \%$ only annually or never. Services per pregnancy was looked at weekly or monthly by $59 \%$ (n $=473$ ) of the producers, even though it is highly biased because, as explained by LeBlanc (2005), it does not account for cows that were not inseminated or for variation in the interval postpartum at AI. Calving interval was looked at weekly or monthly by $62 \%(\mathrm{n}=499)$ of the respondents, but it does not directly measure the efficiency or success of AI, and does not account for the eligible animals that have not been inseminated or do not calve again (LeBlanc, 2005). Age and the highest completed level of education of the respondents were not associated with the use of the different measures. As measures of performance are not equal, it would have been interesting to know what the respondents were thinking when they selected performance as the main influence in their decisions about management of reproduction. Pregnancy rate varied considerably among herds even though respondents reported that the main factor influencing reproductive management decisions was performance. Yet, the data collectively do not point to management decisions that reflect a strong focus on attaining the highest possible PR. It would be interesting to explore how respondents assessed performance (i.e., scientific and extension publications, personal, veterinarians' and neighbors' experience, intuition, and so on). The frequent use of timed AI in

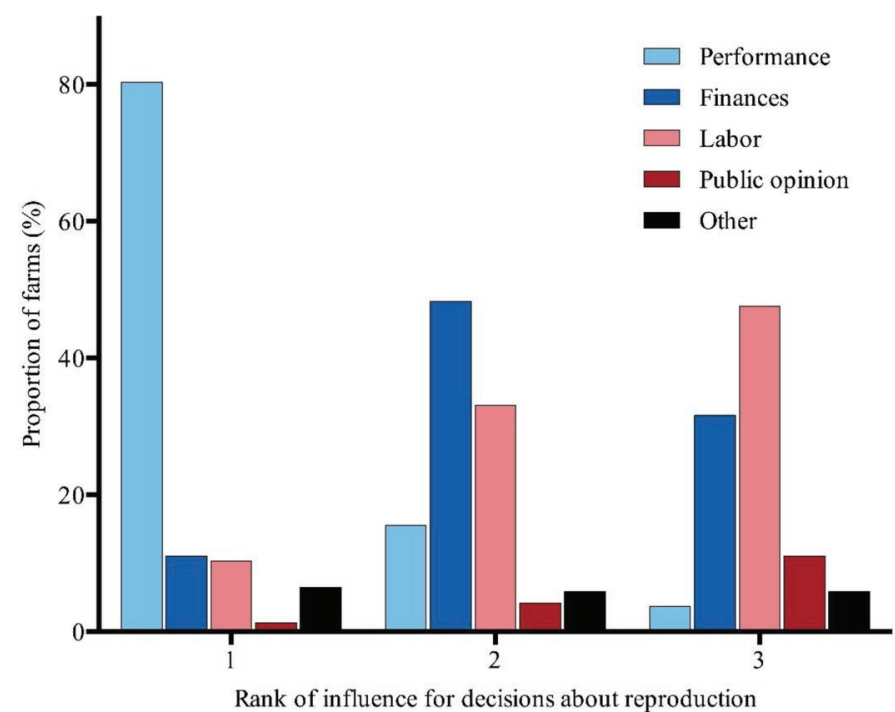

Figure 7. Distribution of the top 3 factors that influenced respondents' decisions about reproduction $(\mathrm{n}=792)$. Color version available online.
There is a significant potential profit if my herd's pregnancy rate increased

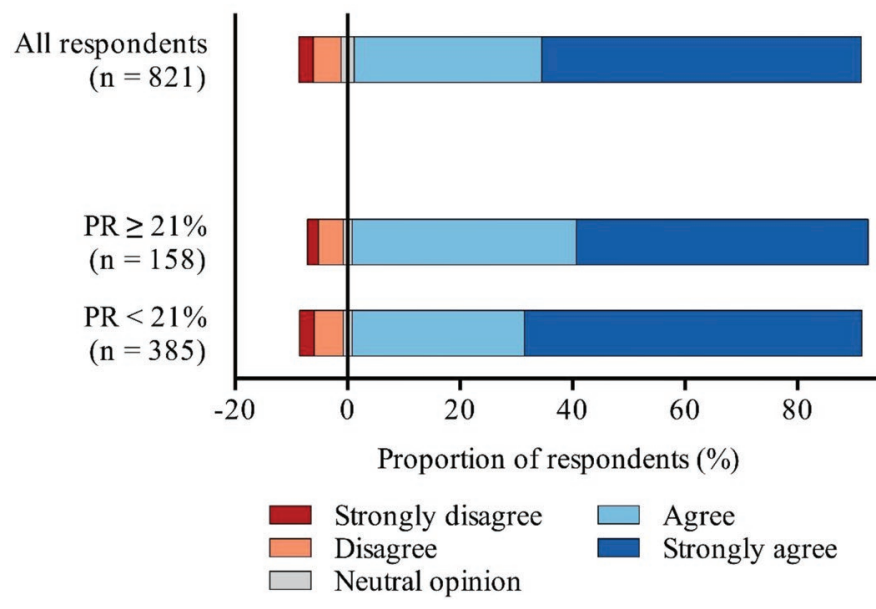

Figure 8. Opinions of 821 dairy producers in Canada on the potential profit associated with increasing of pregnancy rate (PR), categorized by whether or not the herd's actual PR was in the top quartile of respondents' herds $(\mathrm{n}=543)$. Color version available online.

tiestalls might be a reflection of the desire to achieve better performance in a context of limited estrus detection.

Finally, it seems that respondents perceived higher PR as profitable for their business (Figure 8). That perception was the same among all respondents, regardless of their herd's PR. The present study did not explore the reasons why respondents thought there was a significant potential profit to increase the $\mathrm{PR}$ in their herd, but it is possible that respondents also considered opportunities for herd expansion or health and genetic improvement as sources for additional revenue.

\section{CONCLUSIONS}

This study explored the attitudes toward reproductive management and performance of Canadian dairy producers, and the challenges they faced related to reproduction and reproductive management practices. Reproduction of lactating dairy cows was the most important of 9 challenges respondents reported facing on their farms. Multiple difficulties and challenges concerning reproduction were mentioned by the respondents. Estrus detection and conception risk were 2 major concerns that encompassed multiple components. Performance was the main factor influencing the respondents' decisions concerning reproduction. Respondents using timed AI and AAM systems perceived that PR would be higher in their herd with these tools than with visual estrus detection. The results presented here could be useful to farm advisors in approaching reproductive problems on dairy farms, and to inform 
future research with the perspectives of Canadian dairy farmers on reproduction management practices.

\section{ACKNOWLEDGMENTS}

This project was funded by the Dairy Research Cluster Initiative II [Dairy Farmers of Canada (Ottawa, Canada), Agriculture and Agri-Food Canada (Ottawa, Canada), the Canadian Dairy Network (Guelph, Canada), and the Canadian Dairy Commission (Ottawa, Canada)]. We thank Canwest DHI (Guelph, Canada), and Valacta (Sainte-Anne-de-Bellevue, Canada) for their support and appreciate the participation of all farmers in the survey. We are also grateful to Jocelyn Dubuc (Faculté de Médecine Vétérinaire, SaintHyacinthe, Canada) for help developing the questionnaire, Rebecca Vandormael (Bureau Vétérinaire de l'Islet, Saint-Jean-Port-Joli, Canada) for her role in the translation process, and Benjamin Potvin (Ontario Veterinary College, Guelph, Canada) for entering the questionnaire data.

\section{REFERENCES}

Attride-Stirling, J. 2001. Thematic networks: an analytic tool for qualitative research. Qual. Res. 1:385-405. https://doi.org/10.1177/ 146879410100100307.

Bamber, R. L., G. E. Shook, M. C. Wiltbank, J. E. Santos, and P. M. Fricke. 2009. Genetic parameters for anovulation and pregnancy loss in dairy cattle. J. Dairy Sci. 92:5739-5753. https://doi.org/10 $.3168 /$ jds.2009-2226.

Bauman, C. A., H. W. Barkema, J. Dubuc, G. P. Keefe, and D. F. Kelton. 2016. Identifying management and disease priorities of Canadian dairy industry stakeholders. J. Dairy Sci. 99:10194-10203. https://doi.org/10.3168/jds.2016-11057.

Cabrera, V. E. 2014. Economics of fertility in high-yielding dairy cows on confined TMR systems. Animal 8(Suppl. 1):211-221. https:// doi.org/10.1017/S1751731114000512.

Canadian Dairy Information Center. 2014. Overview of the Canadian dairy industry at the farm. Accessed Jun. 5, 2014. http://dairyinfo .gc.ca/index_e.php?s1=dff-fcil\&s2 $=$ farm-ferme\&s3 $=$ nb.

Caraviello, D. Z., K. A. Weigel, P. M. Fricke, M. C. Wiltbank, M. J. Florent, N. B. Cook, K. V. Nordlund, N. R. Zwald, and C. L. Rawson. 2006. Survey of management practices on reproductive performance of dairy cattle on large US commercial farms. J. Dairy Sci. 89:4723-4735. https://doi.org/10.3168/jds.S0022 $-0302(06) 72522-\mathrm{X}$

Chapinal, N., S. J. LeBlanc, M. E. Carson, K. E. Leslie, S. Godden, M. Capel, J. E. P. Santos, M. W. Overton, and T. F. Duffield. 2012. Herd-level association of serum metabolites in the transition period with disease, milk production, and early lactation reproductive performance. J. Dairy Sci. 95:5676-5682. https://doi.org/10 $.3168 /$ jds.2011-5132.

Chebel, R. C., J. E. Santos, J. P. Reynolds, R. L. Cerri, S. O. Juchem, and M. Overton. 2004. Factors affecting conception rate after artificial insemination and pregnancy loss in lactating dairy cows. Anim. Reprod. Sci. 84:239-255. https://doi.org/10.1016/j .anireprosci.2003.12.012.

Denis-Robichaud, J., R. L. Cerri, A. Jones-Bitton, and S. J. LeBlanc. 2016. Survey of reproduction management on Canadian dairy farms. J. Dairy Sci. 99:9339-9351. https://doi.org/10.3168/ jds.2016-11445.

Denis-Robichaud, J., and J. Dubuc. 2015. Determination of optimal diagnostic criteria for purulent vaginal discharge and cytological endometritis in dairy cows. J. Dairy Sci. 98:6848-6855. https://doi .org/10.3168/jds.2014-9120.

Dillman, D. A., J. D. Smyth, and L. M. Christian. 2008. Internet, Mail, and Mixed-Mode Surveys: The Tailored Design Method. 3rd ed. John Wiley \& Sons, Hoboken, NJ.

Dubuc, J., T. F. Duffield, K. E. Leslie, J. S. Walton, and S. J. LeBlanc. 2012. Risk factors and effects of postpartum anovulation in dairy cows. J. Dairy Sci. 95:1845-1854. https://doi.org/10.3168/ jds.2011-4781.

Garcia, J., J. Evans, and M. Reshaw. 2004. "Is There Anything Else You Would Like to Tell Us"-Methodological issues in the use of free-text comments from postal surveys. Qual. Quant. 38:113-125. https://doi.org/10.1023/B:QUQU.0000019394.78970.df.

Gröhn, Y. T., and P. J. Rajala-Schultz. 2000. Epidemiology of reproductive performance in dairy cows. Anim. Reprod. Sci. 60-61:605614. https://doi.org/10.1016/S0378-4320(00)00085-3.

Jeong, H., D. Gonzalez-Pena, T. M. Goncalves, P. J. Pinedo, J. E. P. Santos, G. M. Schuenemann, G. J. M. Rosa, R. O. Gilbert, R. C. Bicalho, R. Chebel, K. N. Galvão, C. M. Seabury, W. W. Thatcher, and S. L. Rodriguez Zas. 2016. Genetic parameters and impact of postpartum diseases on lactation curves in dairy cattle. J. Dairy Sci. 99(E-Suppl.1):63-64. (Abstr.)

LeBlanc, S. 2005. Overall reproductive performance of Canadian dairy cows: Challenges we are facing. Adv. Dairy Technol. 17:137-157.

Löf, E., H. Gustafsson, and U. Emanuelson. 2014. Factors influencing the chance of cows being pregnant 30 days after the herd voluntary waiting period. J. Dairy Sci. 97:2071-2080. https://doi.org/ $10.3168 /$ jds.2012-5874.

Lopez, H., L. D. Satter, and M. C. Wiltbank. 2004. Relationship between level of milk production and estrous behavior of lactating dairy cows. Anim. Reprod. Sci. 81:209-223. https://doi.org/10 .1016/j.anireprosci.2003.10.009.

Løvendahl, P., and M. G. Chagunda. 2010. On the use of physical activity monitoring for estrus detection in dairy cows. J. Dairy Sci. 93:249-259. https://doi.org/10.3168/jds.2008-1721.

Madureira, A. M., B. F. Silper, T. A. Burnett, L. Polsky, L. H. Cruppe, D. M. Veira, J. L. Vasconcelos, and R. L. Cerri. 2015. Factors affecting expression of estrus measured by activity monitors and conception risk of lactating dairy cows. J. Dairy Sci. 98:7003-7014. https://doi.org/10.3168/jds.2015-9672.

Maldonado, G., and S. Greenland. 1993. Simulation study of confounder-selection strategies. Am. J. Epidemiol. 138:923-936.

Morris, M. J., K. Kaneko, S. L. Walker, D. N. Jones, J. E. Routly, R. F. Smith, and H. Dobson. 2011. Influence of lameness on follicular growth, ovulation, reproductive hormone concentrations and estrus behavior in dairy cows. Theriogenology 76:658-668. https:// doi.org/10.1016/j.theriogenology.2011.03.019.

Nebel, R. L., W. L. Walker, M. L. McGilliard, C. H. Allen, and G. S. Heckman. 1994. Timing of artificial insemination of dairy cows: Fixed time once daily versus morning and afternoon. J Dairy Sci 77(10):3185-3191. J. Dairy Sci. 77:3185-3191. https://doi.org/10 .3168/jds.S0022-0302(94)77261-1.

Neves, R. C., and S. J. LeBlanc. 2015. Reproductive management practices and performance of Canadian dairy herds using automated activity-monitoring systems. J. Dairy Sci. 98:2801-2811. https://doi.org/10.3168/jds.2014-8221.

Norman, G. 2010. Likert scales, levels of measurement and the "laws" of statistics. Adv. Health Sci. Educ. Theory Pract. 15:625-632. https://doi.org/10.1007/s10459-010-9222-y.

O'Cathain, A., and K. J. Thomas. 2004. "Any other comments?" Open questions on questionnaires - A bane or a bonus to research? BMC Med. Res. Methodol. 4:25 https://doi.org/10.1186/1471-2288-4 -25 .

Pereira, M. H., M. C. Wiltbank, and J. L. Vasconcelos. 2016. Expression of estrus improves fertility and decreases pregnancy losses in lactating dairy cows that receive artificial insemination or embryo transfer. J. Dairy Sci. 99:2237-2247. https://doi.org/10.3168/jds .2015-9903.

Robbins, N. B., and R. M. Heiberger. 2011. Plotting Likert and other rating scales. Joint Statistical Meeting, Miami Beach, FL. American Statistical Association, Washington, DC. 1058-1066. (Abstr.) 
Roelofs, J. B., F. J. C. M. van Eerdenburg, N. M. Soede, and B. Kemp. 2005a. Pedometer readings for estrous detection and as predictor for time of ovulation in dairy cattle. Theriogenology 64:1690-1703. https://doi.org/10.1016/j.theriogenology.2005.04.004.

Roelofs, J. B., F. J. C. M. van Eerdenburg, N. M. Soede, and B. Kemp. 2005b. Various behavioral signs of estrous and their relationship with time of ovulation in dairy cattle. Theriogenology 63:13661377. https://doi.org/10.1016/j.theriogenology.2004.07.009.

Rutherford, A. J., G. Oikonomou, and R. F. Smith. 2016. The effect of subclinical ketosis on activity at estrus and reproductive performance in dairy cattle. J. Dairy Sci. 99:4808-4815. https://doi.org/ $10.3168 /$ jds.2015-10154.

Santos, J. E., H. M. Rutigliano, and M. F. Sá Filho. 2009. Risk factors for resumption of postpartum estrous cycles and embryonic survival in lactating dairy cows. Anim. Reprod. Sci. 110:207-221. https://doi.org/10.1016/j.anireprosci.2008.01.014.

Schüller, L. K., and W. Heuwieser. 2016. Measurement of heat stress conditions at cow level and comparison to climate conditions at stationary locations inside a dairy barn. J. Dairy Res. 83:305-311. https://doi.org/10.1017/S0022029916000388.

Simensen, E., O. Østerås, K. E. Bøe, C. Kielland, L. E. Ruud, and G. Naess. 2010. Housing system and herd size interactions in Norwegian dairy herds; associations with performance and disease incidence. Acta Vet. Scand. 52:14. https://doi.org/10.1186/1751-0147 $-52-14$

Souza, A. H., H. Ayres, R. M. Ferreira, and M. C. Wiltbank. 2008. A new presynchronization system (Double-Ovsynch) increases fertil- ity at first postpartum timed AI in lactating dairy cows. Theriogenology 70:208-215. https://doi.org/10.1016/j.theriogenology .2008.03.014.

Van Eerdenburg, F. J. C. M., D. Karthaus, M. A. M. Taverne, I. Mercis, and O. Szenci. 2002. The relationship between estrous behavioral score and time of ovulation in dairy cattle. J. Dairy Sci. 85:1150-1156. https://doi.org/10.3168/jds.S0022-0302(02)74177 -5 .

von Keyserlingk, M. A., N. P. Martin, E. Kebreab, K. F. Knowlton, R. J. Grant, M. Stephenson, C. J. Sniffen, J. P. Harner, A. D Wright, and S. I. Smith. 2013. Invited review: Sustainability of the US dairy industry. J. Dairy Sci. 96:5405-5425. https://doi.org/10 $.3168 /$ jds.2012-6354.

Walker, S. L., R. F. Smith, J. E. Routly, D. N. Jones, M. J. Morris, and H. Dobson. 2008. Lameness, activity time-budgets, and estrus expression in dairy cattle. J. Dairy Sci. 91:4552-4559. https://doi .org/10.3168/jds.2008-1048.

Walsh, R. B., D. F. Kelton, T. F. Duffield, K. E. Leslie, J. S. Walton, and S. J. LeBlanc. 2007. Prevalence and risk factors for postpartum anovulatory condition in dairy cows. J. Dairy Sci. 90:315-324. https://doi.org/10.3168/jds.S0022-0302(07)72632-2.

Wiltbank, M. C., and J. R. Pursley. 2014. The cow as an induced ovulator: Timed AI after synchronization of ovulation. Theriogenology 81:170-185. https://doi.org/10.1016/j.theriogenology.2013.09.017. 